\title{
Can Dipeptidyl Peptidase 4 Inhibitor Be the Therapeutic Candidate for the COVID-19?
}

\author{
Hidekatsu Yanaia, b, c
}

Severe acute respiratory syndrome coronavirus 2 (SARSCoV-2), which causes coronavirus disease 2019 (COVID-19) has reached a pandemic level. There is an urgent need for effective treatment. Dipeptidyl peptidase 4 (DPP4; also known as cluster of differentiation $26(\mathrm{CD} 26)$ ) was identified as a functional receptor for the Middle East respiratory syndrome coronavirus (MERS-CoV) [1]. It has been speculated that the preferential spatial localization of DPP4 in alveolar regions may explain why MERS is characterized by lower respiratory tract diseases [2], and such characteristic was also observed in COVID-19. The S1 domain of SARS-CoV-2 spike glycoprotein potentially interacts with the human CD26, a key immunoregulatory factor for hijacking and virulence [3].

The widespread expression of DPP4 on blood vessels, myocardium, and myeloid cells and function of CD26 as a signaling and binding protein suggest a crucial role in cardiovascular regulation and inflammation [4]. DPP4 is upregulated in proinflammatory states such as obesity, diabetes and atherosclerotic diseases [4]. In a recent retrospective cohort study of COVID-19, comorbidities were present in nearly half of patients, with hypertension $(30 \%)$ being the most common comorbidity, followed by diabetes (19\%) and coronary artery disease (8\%) [5]. In univariable analysis, odds of in-hospital death were significantly higher in patients with diabetes (2.85) or coronary artery disease (21.40) [5]. DPP4 inhibitor is the most commonly used oral antidiabetic drug, and its safety is excellent. The sub-analysis of COVID-19 retrospective cohort studies which evaluate the influence of DPP4 inhibitor use on severity, morbidity and mortality in diabetic patients may assist in the development of new therapeutics for COVID-19.

\section{Acknowledgments}

None to declare.

Manuscript submitted April 19, 2020, accepted April 27, 2020

aDepartment of Diabetes, Endocrinology and Metabolism, National Center for Global Health and Medicine Kohnodai Hospital, Chiba, Japan

${ }^{b}$ Department of Internal Medicine, National Center for Global Health and Medicine Kohnodai Hospital, 1-7-1 Kohnodai, Ichikawa, Chiba 272-8516, Japan ${ }^{\mathrm{c} C}$ Corresponding Author: Hidekatsu Yanai, Department of Internal Medicine, National Center for Global Health and Medicine Kohnodai Hospital, 1-7-1 Kohnodai, Ichikawa, Chiba 272-8516, Japan. Email: dyanai@hospk.ncgm.go.jp

\section{Financial Disclosure}

None to declare.

\section{Conflict of Interest}

None to declare.

\section{Author Contributions}

HY wrote and approved the final paper.

\section{Data Availability}

The author declares that data supporting the findings of this study are available within the article.

\section{References}

1. Raj VS, Mou H, Smits SL, Dekkers DH, Muller MA, Dijkman R, Muth D, et al. Dipeptidyl peptidase 4 is a functional receptor for the emerging human coronavirusEMC. Nature. 2013;495(7440):251-254.

2. Meyerholz DK, Lambertz AM, McCray PB, Jr. Dipeptidyl Peptidase 4 Distribution in the Human Respiratory Tract: Implications for the Middle East Respiratory Syndrome. Am J Pathol. 2016;186(1):78-86.

3. Vankadari N, Wilce JA. Emerging WuHan (COVID-19) coronavirus: glycan shield and structure prediction of spike glycoprotein and its interaction with human CD26. Emerg Microbes Infect. 2020;9(1):601-604.

4. Zhong J, Maiseyeu A, Davis SN, Rajagopalan S. DPP4 in cardiometabolic disease: recent insights from the laboratory and clinical trials of DPP4 inhibition. Circ Res. 2015;116(8):1491-1504.

5. Zhou F, Yu T, Du R, Fan G, Liu Y, Liu Z, Xiang J, et al. Clinical course and risk factors for mortality of adult inpatients with COVID-19 in Wuhan, China: a retrospective cohort study. Lancet. 2020;395(10229):1054-1062. 